\title{
Generic characterization method for energy flexibility: applied to structural thermal storage in residential buildings
}

\author{
Glenn Reynders ${ }^{\mathrm{a}, \mathrm{b}}$, Jan Diriken ${ }^{\mathrm{c}, \mathrm{b}}$, Dirk Saelens ${ }^{\mathrm{a}, \mathrm{b}}$ \\ ${ }^{a}$ KU Leuven, Building Physics Section, Kasteelpark Arenberg 40 box 2447, BE-3001 \\ Heverlee, Belgium \\ ${ }^{b}$ EnergyVille, Thor park 8310, BE-3600 Genk, Belgium \\ ${ }^{c}$ VITO, Unit Energy Technology, Boeretang 200, BE-2400 Mol, Belgium
}

\begin{abstract}
The use of structural thermal storage is often suggested as a key technology to improve the penetration of renewable energy sources and mitigate potential production and distribution capacity issues. Therefore, a quantitative assessment of the energy flexibility provided by structural thermal energy storage is a prerequisite to instigate a large scale deployment of thermal mass as active storage technologies in an active demand response (ADR) context.

In the first part of the work, a generic, simulation-based and dynamic quantification method is presented for the characterization of the ADR potential, or energy flexibility, of structural thermal energy storage. The quantification method is based on three ADR characteristics - i.e. available storage capacity, storage efficiency and power-shifting capability - which can be used to quantify the ADR potential in both design and operation.

In the second part of the work, the methodology is applied to quantify the ADR characteristics for the structural thermal energy storage capacity for the different typologies of the Belgian residential building stock. Thereby an in-depth analysis demonstrates the relation between the building properties and its energy flexibility as well as the dependence of the energy flexibility on the dynamic boundary conditions.
\end{abstract}

Keywords: Energy flexibility, Active demand response, Thermal storage

\section{Introduction}

In order to avoid potential grid stability issues [1] associated with a high penetration of renewable energy sources and the electrification of the energy demand, active demand response (ADR) is often suggested [2, 3. In that context

\footnotetext{
${ }^{*}$ Corresponding author

Email address: glenn.reynders@kuleuven.be (Glenn Reynders)

$U R L$ : www. bwk. kuleuven.be/bwf (Glenn Reynders)
} 
buildings may also play a significant role as they not only represent $40 \%$ of the total energy use world-wide, but - by taking into account their potential for thermal energy storage - they also show an important flexibility for active demand response ${ }^{1}$ [4, 5, 6. Using conversion technologies such as energy efficient heat pumps to convert power to heat, thermal energy storage is shown to be a low-cost alternative for direct electrical storage 7]. Moreover, thermal energy storage is widely distributed in the building sector as hot water storages or the thermal mass of the building structure, referred to as structural thermal energy storage (STES).

The potential of thermal energy storage - and more specific structural thermal energy storage - for ADR is commonly evaluated in case studies, demonstrating the impact of using STES to shift the peak heating and cooling demand, to increase the passive use of solar and internal gains or maximize the benefits of varying energy prices $[8,4,9,10$. On the one hand, these studies demonstrate significant energy cost savings, increased uptake of renewable production and greenhouse gas emission reductions when the available flexibility of the thermal mass of the building is used to optimize the buildings energy demand profile. On the other hand, a comparison of these studies shows that the results are highly case dependent. Conclusions based on this type of studies on the available flexibility of STES for ADR are difficult to generalize since energy (cost) savings demonstrated in those case studies depend upon amongst others the specific energy market context or the penetration rate and mix of renewable energy sources.

To allow a case independent analysis of the energy flexibility - enabling the comparison of the potential for ADR between different buildings and even between different storage technologies - recent studies have proposed generic quantification methods for the ADR potential of thermal energy storage. In general these quantification methods approach the assessment of the demand response potential or energy flexibility by quantifying the properties of an equivalent storage unit. This approach is introduced in Heussen et al. [11. The study presented the 'power node framework' that models demand response technologies as generic virtual storage units, characterized by the storage capacity $C$, the state of charge, the efficiency of the conversion process and the storage losses or storage efficiency. A similar, generic approach - i.e. the concept of 'Energy Hubs' - was introduced in the 'Vision of Future Energy Networks' project [12. Their main strength thereby lays in the generic description of demand response and storage technologies, allowing for a combined evaluation of a large mix of technologies. Nevertheless, in the context of structural thermal storage in buildings the challenge however still lays in finding an appropriate translation from the buildings thermal properties and dynamic thermal response to the equivalent storage, or power node, properties. As a first step, this work aims at gaining insight into this relation between building thermal properties and the

\footnotetext{
${ }^{1}$ Active demand response (ADR) is defined as a temporary deviation of the energy demand compared to the reference scenario, without influencing the normal operation of the building
} 
resulting demand reponse potential, by providing and applying a comprehensive quantification framework for demand response characteristics.

As an alternative to [11, Oldewurtel et al. [13] extended the use of traditional performance indicators for storage systems - such as the energy capacity, the maximum (dis)charge power, the autonomy etc. - to demand response technologies, contrasting amongst others the power capacity, energy capacity, ramp rate and response time of both storage and DR technologies. Using a similar, optimal control-based approach, De Coninck et al. 14] assess flexibility by quantifying the available storage capacity in relation to the (energy) cost associated to activating the storage capacity. While the latter methods show large similarities with the ADR characteristics and quantification methods developed in this paper, De Coninck et al. 14] and Oldewurtel et al. 13] start from an optimal control formulation for the quantification methods. In this paper, the quantification methods are developed from the analysis of single ADR events. Moreover, the formulations used in this paper start form a rule-based control. Although the authors acknowledge that the optimal control formulation has important benefits in operational control applications and analysis of more complex systems, the rule-based control approach is exploited in this paper to establish a comprehensive analysis of the relation between the building design and its energy flexibility. Such an in-depth analysis of this relationship performed by a quantification of the energy flexibility of building typologies has to the authors knowledge not yet been established.

In this work, based on a review and the identified overlap of the literature presented above, 3 ADR characteristics are deduced and applied to quantify the ADR potential of STES in the Belgian residential sector. Section 2 presents the definitions and quantification methods for the ADR characteristics. Section 3 briefly summarizes the Belgian building stock model and the simulation approach used to quantify the indicators. The results are discussed in Section 4 for a theoretic case using respectively simplified (4.1) and dynamic $(4.2)$ boundary conditions. The simplified boundary conditions are used to highlight the impact of the building design on the ADR potential, the latter demonstrate the impact of dynamic boundary conditions. The main conclusions and suggestions for future research are summarized in Section 5 ,

\section{Definition of generic ADR characteristics}

In this section, 3 performance indicators or characteristics for ADR are defined and quantification methods for the ADR potential of structural thermal storage are presented. These characteristics are chosen as they cover 3 main dimensions of energy flexibility that were identified in the literature review in section 1 i.e. the dimensions of size, time and cost. In this work specifically the available storage capacity $\left(C_{\mathrm{ADR}}\right)$, the storage efficiency $\left(\eta_{\mathrm{ADR}}\right)$ and the power shifting capability $(P S C)$ are presented. Thereby $C_{\mathrm{ADR}}$ and $P S C$ cover the dimension of size as they represent respectively the energy and the power that can be shifted. In addition, the $P S C$ includes the relation between the dimensions of size and time. The storage efficiency $\left(\eta_{\mathrm{ADR}}\right)$ is defined to acknowledge 


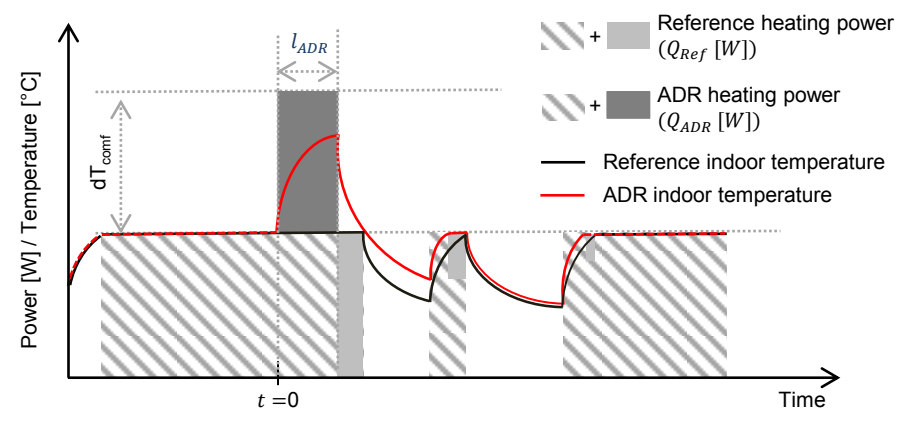

Figure 1: Conceptual representation of the simulation experiment used to quantify the available storage capacity and the storage efficiency

that activating thermal storage for demand response will induce storage losses and hence a cost for activating this storage capacity.

Note that the definitions given below are readily extended to cooling application. Also, since this study focuses on the relation between the ADR potential and the thermal properties of the building structure rather than the thermal system properties, the heating power in this paper corresponds to the net heating power emitted by the emission system to the building and not the produced power of the heating system. In other words, potential system losses or the impact of ADR on for instance the coefficient of performance of heat pumps are not taken into account in this work. A distinction has been made between radiator and floor heating systems, as the use of these systems has a major impact on how the structural thermal storage capacity is activated.

\subsection{Available structural storage capacity}

The available storage capacity expresses the amount of energy that can be added to the STES during a specific ADR event. Thereby, the heat that can be stored within a dwelling not only depends upon the thermal properties of the building fabric, but also on the properties and actual use of the heating and ventilation systems. Moreover for structural thermal mass these performance indicators are, in contrast to f.i. batteries, not constant but vary with the climatic boundary condition and occupant behavior. The definition therefore explicitly takes into account the time-depend aspect. The evaluation of such discrete events was also evaluated in [13, 14, 15, 16] and was found to be a comprehensive manner to capture the ADR potential from the dynamic response of the building mass, goverened by multiple time constants.

Definition. The available capacity for active demand response $\left(C_{\mathrm{ADR}}[\mathrm{kWh}]\right)$ is defined as the amount of energy that can be added to the storage system, without jeopardizing comfort, in the time-frame of an ADR-event and given the dynamic boundary conditions. 
Quantification. To quantify the available storage capacity, the thermal response of a building during an ADR event is analyzed. The ADR event (schematized in Fig. 1) is simulated starting from a building with an indoor temperature equal to the minimum comfort temperature. During the ADR event the temperature set point for the heating systems in increased by $d T_{\text {comf }}\left[{ }^{\circ} \mathrm{C}\right]$ for the duration $l_{\mathrm{ADR}}[\mathrm{s}] . C_{\mathrm{ADR}}$ is then given by the integral of the difference between the heating power during this $\mathrm{ADR}$ event $\left(Q_{\mathrm{ADR}}[\mathrm{W}]\right)$ and the heating power in normal operation $\left(Q_{R e f}[\mathrm{~W}]\right)$, represented by the dark gray area in Figure 1 .

$$
C_{\mathrm{ADR}}=\int_{0}^{l_{\mathrm{ADR}}}\left(Q_{\mathrm{ADR}}-Q_{R e f}\right) d t
$$

As stated the heating profile $Q_{\text {Ref }}$ corresponds to the profile that keeps the temperature equal to the minimum comfort temperature which is assumed to correspond to a scenario whereby the heat demand is minimized at building leve 2 . Consequently, only upward flexibility is considered when analyzing $C_{\mathrm{ADR}}$ in the current work implying that in a first step a building will try to minimize its own consumption before providing flexibility to the grid. $C_{\mathrm{ADR}}$ thus represents the maximum amount of heat that can be stored in the structural storage capacity of the building in $l_{\mathrm{ADR}}$, given the boundary conditions for thermal comfort, climate, occupant behavior. Due to the latter, it is evident that the available storage capacity - as well as the storage efficiency defined below - are not constant, but vary in time depending on the boundary conditions.

Moreover, it should be noted that $C_{\mathrm{ADR}}$ reflects the perspective from the grid as it covers the gross amount of energy shifted on the energy network. Building managers on the other hand may be more interested in the net heat that can be buffered, taking into account the storage losses. Therefore, the next paragraph introduces the storage efficiency. The combination of both characteristics is hence important when analyzing the ADR potential of thermal storage technologies.

\subsection{Storage Efficiency}

As shown in [9, 17, the activation of the storage capacity results in an increased temperature within the building and thus the transmission, ventilation and infiltration losses increase. Consequently, only a part of the stored heat can be used effectively to maintain thermal comfort and reduce the heating power in the period following the ADR event.

Definition. The storage efficiency $\left(\eta_{\mathrm{ADR}}[-]\right)$ is defined as the fraction of the heat that is stored during the ADR event that can be used subsequently to reduce the heating power needed to maintain thermal comfort.

\footnotetext{
${ }^{2}$ Other reference profiles or the actual state of charge of a building may be used, for example as done in Figure 4 to predict the instantaneous values of $C_{\mathrm{ADR}}$. Depending on the reference profile this may also unlock negative capacities for downward modulation.
} 
Quantification. The efficiency is calculated using the same 2 simulation scenarios, i.e. the ADR event and the reference scenario, that are used to quantify the storage capacity (Figure 1). Given these simulations, the efficiency is calculated as:

$$
\eta_{\mathrm{ADR}}=1-\frac{\int_{0}^{\infty}\left(Q_{\mathrm{ADR}}-Q_{R e f}\right) d t}{\int_{0}^{l_{\mathrm{ADR}}}\left(Q_{\mathrm{ADR}}-Q_{R e f}\right) d t}
$$

The integral in the denominator equals the heat stored in the storage event or the available storage capacity $\left(C_{\mathrm{ADR}}\right)$, shown as the dark gray area in Figure 1 . A part of this heat can be used after the ADR event to reduce the heating power needed to guarantee thermal comfort. This reduction in power is indicated by the light gray area in Figure 1. The storage losses induced by activating the thermal mass - i.e. the numerator in equation 2 - thus correspond to the fraction of the heat stored during the ADR event that is not recovered after a long period.

\subsection{Power shifting capability}

Whereas $C_{\mathrm{ADR}}$ and $\eta_{\mathrm{ADR}}$ can be interpreted as characteristic properties of the building in a design stage, the power shifting capability is a measure for the instantaneous energy flexibility. In contrast to the state of charge - which is a single value often used in electric storage systems that represents the energy content of a storage medium - the power shifting capability describes the relation between the shift in power that can be obtained at a given moment in time and the duration this shift can be maintained.

Definition. The power shifting capability is the relation between the change in heating power $\left(Q_{\delta}\right)$ and the duration $\left(t_{\delta}\right)$ that this shift can maintained, taking into account the future boundary conditions, before the normal operation of the system, i.e. thermal comfort, is jeopardized.

Quantification method. Starting from the building at state $X_{0}$ and assuming predictions of the future boundary conditions, the thermal response of the building to a step-change in the heating power is simulated. The power shift $\left(Q_{\delta}[W]\right)$ is defined as the difference between the heating power during the ADR event $\left(Q_{\mathrm{ADR}}[W]\right)$ and the reference heating power $\left(Q_{\text {Ref }}[W]\right)$ during normal operation. This difference is evidently constraint by the physical boundaries of the system.

$$
Q_{\delta}=Q_{\mathrm{ADR}}-Q_{R e f}
$$

The duration this shift can be maintained $\left(t_{\delta}\right)$ is then calculation as the duration until the thermal comfort boundaries, either $T_{\max }$ or $T_{\min }$, are reached. The power shifting capability is then expressed as $t_{\delta}\left(Q_{\delta}\right)$.

A distinction is made between the upward and downward shifting capability, representing respectively an increase or a decrease of the heating power compared to the current state. 
Table 1: Overview of the analyzed building cases

\begin{tabular}{ll} 
Building type: & Detached (D), Semi-Detached (SD), Terraced (T) \\
Age classes: & pre '45 (1), '46-'70 (2), '71-'90 (3), '91-'05 (4), post '05 (5) \\
Renovation: & Original (Org), Mild renovation (Ref. 1), heavy renovation (Ref. 2) \\
\hline
\end{tabular}

\section{Belgian building stock model}

In this section the building typologies used in the development of a bottomup dynamic building stock model for the Belgian residential building sector is presented. The building stock model implemented in this paper is based on the model presented in [18] and consists of detailed building energy simulation models for each of the typical building typologies. These typologies cover the wide range of different topologies, age classes and renovation levels and are in line with the European TABULA building stock description.

The following paragraphs briefly summarize the building stock description (3.1) and the models used to accurately simulate the dynamic thermal response of the dwellings (3.2). For a more detailed description we refer to [18. Section 3.3 presents the simplified and dynamic boundary conditions used to analyze the relation between the ADR potential, the building design and the boundary conditions.

\subsection{Building stock description}

The simulation framework follows the TABULA typology approach whereby the building stock is represented by a discrete set of typical buildings for different topologies and age classes.

The geometry and thermal transmittance (U-value) of the envelope components are obtained from the TABULA building stock description [19], together with typical infiltration and ventilation rates. Based on the typical compositions of construction specified in TABULA, the material properties used in the detailed model have been obtained by reverse engineering to match the U-values given in the TABULA specification. The resulting compositions hence also define the available thermal mass, which for the analyzed typologies resulted in medium to heavy buildings. The main assumptions used to extend the single zone stationary building stock description of the TABULA project to a two-zone dynamic building stock model are summarized in [18. In addition to the specification of the original building characteristics according to TABULA, 2 renovation scenarios have been implemented in this work. A basic renovation scenario (Ref. 1) is defined whereby the windows have been upgraded (U-value $=1.8 \mathrm{~W} /\left(\mathrm{m}^{2} \mathrm{~K}\right)$ ), the air tightness is improved $\left(v_{50}=6 \mathrm{~h}^{-1}\right)$ and the roof has been insulated to a U-value of $0.3 \mathrm{~W} /\left(\mathrm{m}^{2} \mathrm{~K}\right)$. In Ref. 2 the outer walls and floor are also insulated in addition to Ref. 1 , to a U-value of $0.3 \mathrm{~W} /\left(\mathrm{m}^{2} \mathrm{~K}\right)$, which is slightly below the 0.4 $\mathrm{W} /\left(\mathrm{m}^{2} \mathrm{~K}\right)$ used in the TABULA specification. These improved U-values have been selected from the renovation scenario proposed in the TABULA project [19] and are considered to be realistic values to be encountered in the existing 


\begin{tabular}{|c|c|c|c|c|c|c|}
\hline Building & $\begin{array}{c}\mathrm{V} \\
{\left[\mathrm{m}^{3}\right]}\end{array}$ & $\begin{array}{c}\mathrm{A}_{\mathrm{f}} \\
{\left[\mathrm{m}^{2}\right]}\end{array}$ & $\begin{array}{c}\text { HTC }_{\text {org }} \\
{[W / K]}\end{array}$ & $\begin{array}{c}\mathrm{HTC}_{R e f 1} \\
{[W / K]}\end{array}$ & $\begin{array}{c}\mathrm{HTC}_{R e f 2} \\
{[W / K]}\end{array}$ & $\begin{array}{c}\mathrm{C}_{\text {tot }} \\
{[M J / K]}\end{array}$ \\
\hline D1 & 766 & 279 & 1268 & 916 & 257 & 197 \\
\hline D2 & 648 & 235 & 1030 & 688 & 241 & 190 \\
\hline D3 & 655 & 238 & 627 & 475 & 274 & 185 \\
\hline D4 & 710 & 258 & 462 & 341 & 267 & 202 \\
\hline D5 & 741 & 270 & 312 & / & l & 217 \\
\hline SD1 & 651 & 237 & 945 & 660 & 198 & 108 \\
\hline SD2 & 513 & 193 & 740 & 508 & 183 & 124 \\
\hline SD3 & 509 & 185 & 465 & 359 & 211 & 126 \\
\hline $\mathrm{SD} 4$ & 616 & 224 & 458 & 335 & 266 & 130 \\
\hline SD5 & 642 & 233 & 262 & / & / & 146 \\
\hline $\mathrm{T} 1$ & 621 & 225 & 712 & 488 & 169 & 127 \\
\hline $\mathrm{T} 2$ & 546 & 199 & 599 & 384 & 159 & 183 \\
\hline T3 & 462 & 168 & 324 & 245 & 156 & 163 \\
\hline $\mathrm{T} 4$ & 526 & 191 & 246 & 179 & 148 & 209 \\
\hline T5 & 550 & 200 & 189 & / & / & 179 \\
\hline
\end{tabular}

building stock. Note that the thermal mass of the dwellings is, apart from the added insulation material, not affected by these renovations.

A summary of the main thermal properties of the analyzed typologies is given in table 2 , more details are found in [18].

\subsection{Building energy simulation model}

The detailed building energy simulation model is implemented using the IDEAS library developed at KU Leuven [20. The IDEAS library is developed in Modelica and expresses transient thermal processes in detail as described in 21.

In order to accurately capture the dynamic behavior of the thermal mass, each material layer of a multi-layered building component is divided in 8 control volumes, which was found to be a good compromise between simulation speed and accuracy [21]. At the inner surface, convective heat transfer is modeled using buoyancy driven, temperature dependent, convection correlations defined by Khalifa et al. 22] and Awbi et al. [23, while short- and long-wave radiation are modeled using the distribution coefficients and star network approach. At the outer surface, the convection correlations presented by Defraeye et. al. 24 are implemented and the long-wave heat transfer model is derived from the Stefan-Boltzmann law using the celestial dome temperature Tsky [25]. A detailed description of all terms is given in 21].

As mentioned above, the dwellings are modeled as two-zone buildings differentiating between the ground floor - which acts as day-zone - and the first and second floor - which act as night-zone. The two-zone approach is used to reflect the significant differences in boundary conditions, i.e. occupancy behavior (3.3).

For each dwelling typology, two types of heat emission systems are analyzed, i.e. a fast responsive radiator system and a floor heating system. The radiator emission system is modeled using a thermal capacity which exchanges heat by radiation $(30 \%)$ and convection $(70 \%)$. The floor heating is modeled as 


\begin{tabular}{|c|c|c|}
\hline Zone & $\begin{array}{l}\text { Temperature setpoints } \\
\text { occupied } \backslash \text { unoccupied }\end{array}$ & Occupied period \\
\hline Day-zone & $21^{\circ} \mathrm{C} \backslash 16^{\circ} \mathrm{C}$ & $07: 00-22: 00$ \\
\hline Night-zone & $18^{\circ} \mathrm{C} \backslash 16^{\circ} \mathrm{C}$ & 21:00-09:00 \\
\hline
\end{tabular}

an ideal heat flow which is introduced uniformly over the floor area at the interface between the concrete and the screed layer. The thermal production unit is modeled in a simplified way as a power limited, ideal heat source. This simplification was made since - as mentioned above - the focus of this paper is on the building thermal dynamics rather than the system efficiency. The system is sized according EN 12831 [26] using the exterior design temperature of -10 ${ }^{\circ} \mathrm{C}$ and controlled by an adjustable thermostatic control (PI control).

\subsection{Boundary conditions}

As will be demonstrated in 4.2 the ADR potential of structural thermal energy storage is highly influenced by dynamic boundary conditions. Therefore, in order to allow a comprehensive analysis of the relation between the building design and the ADR potential on the one hand and between the ADR potential and the boundary conditions on the other hand, two sets of boundary conditions have been implemented.

To demonstrate the impact of the dynamic boundary conditions and hence the time dependent character of the ADR potential of STES, simulations are carried out for the heating dominated climate of Belgium (Uccle). Climate data are obtained from Meteonorm 6.1 27 and provided with a 10 min resolution. Occupant induced internal gains are modeled using the stochastic occupancy model StROBe, developed in Python and described in 28. However, a deterministic schedule is used for the room thermostat as given in table 3 The variation in indoor air temperature that is allowed to activate the thermal mass during the ADR-event is limited to maximum $2{ }^{\circ} \mathrm{C}$, corresponding to the variation observed for traditional heating control [29. Thereby it is noted that the allowed deviation for ADR is always compared to the temperature setpoint of the occupied period.

In addition to the analysis of these dynamic boundary conditions 4.2 , the first part of the analysis (section 4.1) eliminates the influence of dynamic boundary conditions in order to focus on the link between the thermal properties of the building. For these static boundary conditions, the indoor temperature setpoints are kept constant - except during the ADR-event - at $21{ }^{\circ} \mathrm{C}$ and $18{ }^{\circ} \mathrm{C}$ for respectively the day- and night-zone. The outdoor temperature is set to 5 ${ }^{\circ} \mathrm{C}$ which is a representative temperature for the heating season in the Belgian climate. Internal gains and solar gains are omitted.

\section{Results}

In order to gain better insight in the relation between the building design properties and the suitability for active demand response, the theoretical poten- 
tial for ADR using the structural storage capacity is quantified in this section for the different typologies of the Belgian residential building stock. Section 4.1 presents the analysis for static boundary conditions. Thereby the goal is to get insight in the ADR characteristics for the Belgian stock in relation to the building type, age class and renovation level. This evaluation under steady-state conditions is shown to be a comprehensive tool to evaluate the overall performance of thermal storage for active demand response and compare building design measures that support energy flexibility. Nonetheless, the instantaneous values for the ADR characteristics may vary significantly depending on dynamic boundary conditions. Therefore, the impact of dynamic boundary conditions is presented in section 4.2

\subsection{Impact of building design for static boundary conditions}

This section analyses $C_{\mathrm{ADR}}, \eta_{\mathrm{ADR}}$ and $P S C$ under static boundary conditions. This means the ADR step events are simulated assuming constant outdoor temperature, a fixed minimum comfort temperature $\left(20^{\circ} \mathrm{C}\right)$ and in the absence of solar and user gains. The results are calculated for outdoor temperatures of $-5^{\circ} \mathrm{C}, 0^{\circ} \mathrm{C}, 5^{\circ} \mathrm{C}$ and $10^{\circ} \mathrm{C}$ in a sensitivity analysis.

Since $C_{\mathrm{ADR}}$ and $\eta_{\mathrm{ADR}}$ are obtained from the same simulation experiments (Section 22), both indicators are discussed together. Figure 2 shows $C_{\mathrm{ADR}}$ (top) and $\eta_{\mathrm{ADR}}$ (bottom) as a function of the building typology and renovation level for the buildings equipped with radiator heating. For all building cases an increase of $C_{\mathrm{ADR}}$ and a decrease of $\eta_{\mathrm{ADR}}$ are observed for increasing durations of the storage event. The rate of increase is linear for short durations as the heating can operate at maximum power. For longer durations, as the indoor temperature reaches the upper comfort bound, the heating power must be limited to avoid overheating, hence reducing the rate of increase of $C_{\mathrm{ADR}}$.

The decrease in $\eta_{\mathrm{ADR}}$ is caused by the higher indoor temperatures which result in higher thermal losses from longer storage events. For storage events longer than $3 \mathrm{~h}, \eta_{\mathrm{ADR}}$ may decrease as low as $70 \%$ for the unrenovated dwellings. Similar trends are found for the floor heating cases, although both $C_{\mathrm{ADR}}$ and $\eta_{\mathrm{ADR}}$ are in general higher for floor heating as it directly activates the thermal mass and has smaller direct impact on the air temperature.

Contrasting the building thermal properties, Figures 2 (top) shows a significant increase of $C_{\mathrm{ADR}}$ as the age of the dwelling increases and renovation level decreases. Due to the higher nominal heating power that is available for $\mathrm{ADR}, C_{\mathrm{ADR}}$ for the oldest, unrenovated buildings is on average twice the value of $C_{\mathrm{ADR}}$ for the thoroughly renovated buildings. For the same reason, $C_{\mathrm{ADR}}$ is on average $20 \%$ higher for detached dwellings than for semi-detached and terraced houses. When the STES is activated for a period of $4 \mathrm{~h}$ with an allowed temperature increase of $2{ }^{\circ} \mathrm{C}, C_{\mathrm{ADR}}$ varies between $12 \mathrm{kWh}$ for the thoroughly renovated terraced dwellings and $30 \mathrm{kWh}$ for the original detached house built before 1945. As a comparison, this is equivalent to a water storage tank of respectively $520 \mathrm{l}$ and $1300 \mathrm{l}$ assuming that temperature in the storage tank is allowed to increase by $20^{\circ} \mathrm{C}$ for active demand response. A similar study was 


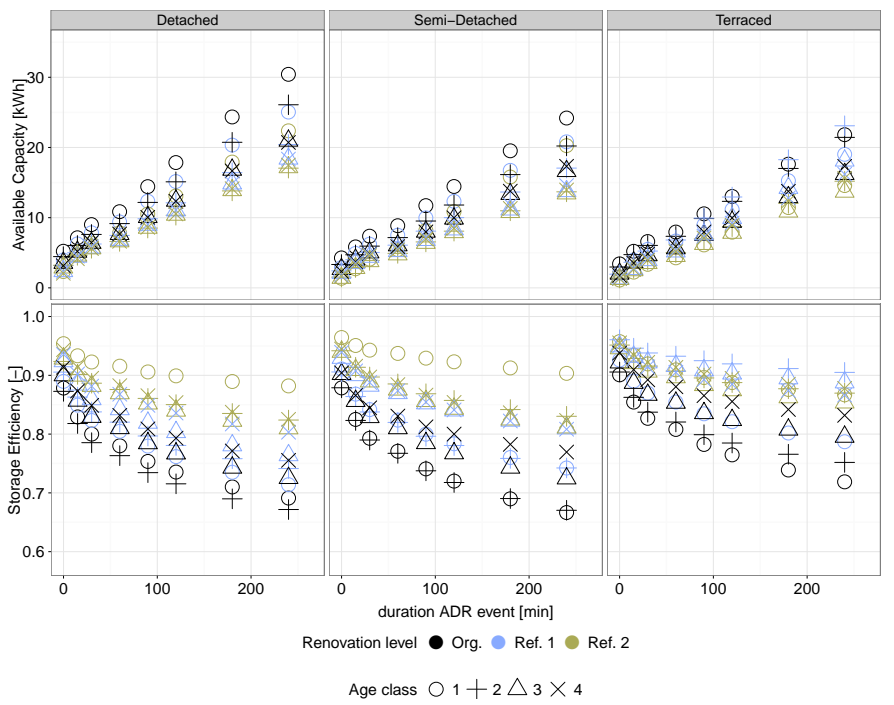

Figure 2: $C_{\mathrm{ADR}}$ (top) and $\eta_{\mathrm{ADR}}$ (bottom) for the different building types, age classes and renovation levels for the radiator heated buildings, a constant outdoor temperature of $5{ }^{\circ} \mathrm{C}$ and comfort range of $2{ }^{\circ} \mathrm{C}$

carried out in 30, comparing the charged heat for different buildings with radiator and floor heating. The obtained storage capacities in that study were in average lower with values $50-80 \mathrm{Wh} / \mathrm{m}$ for a storage event of $2 \mathrm{~h}$, compared to values of $45-120 \mathrm{Wh} / \mathrm{m}$ for the current work. These discrepancies can however be attributed to the differences in boundary conditions and building characteristics.

For the buildings equipped with floor heating similar trends are found. Nevertheless since the thermal mass of the floor is directly activated, the indoor temperature fluctuations are mitigated allowing the heating system to operate longer at maximum power. Hence $C_{\mathrm{ADR}}$ is in general higher for the floor heated buildings, ranging from $16 \mathrm{kWh}$ for the thoroughly renovated terraced dwellings and $66 \mathrm{kWh}$ for the original detached house built before 1945, equivalent to water storage tanks of respectively 690 and $2840 \mathrm{l}$.

$C_{\mathrm{ADR}}$ increases with the heat loss coefficient and the size of the dwellings. Consequently, Figure 2 (top) also demonstrates a reduction of the relative differences between the age classes as buildings are renovated. An exception to this is found for the buildings built before 1945 (Age class 1). For these dwellings the outer walls consists of a $25 \mathrm{~cm}$ brick wall, whereas a cavity wall is used for the newer buildings. The thermal mass inside the insulation layer is thus significantly higher for the oldest period, even though the entire thickness does not contribute equally to the available thermal mass.

The corresponding storage efficiencies are shown in Figure2 (bottom). The $\eta_{\mathrm{ADR}}$ also depends significantly on the heat loss coefficient, as shown by the increasing efficiencies for increasing renovation levels and decreasing age of the 


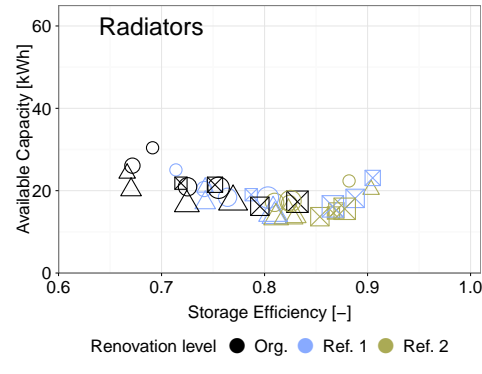

Type $\bigcirc$ Detached $\triangle$ Semi-Detached $\otimes$ Terraced

Age class

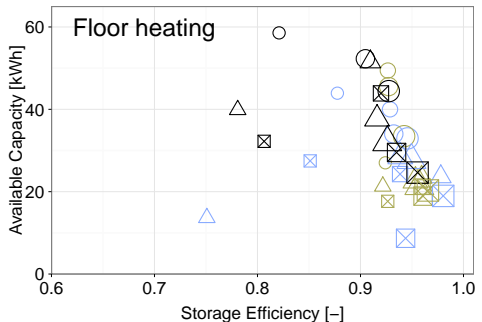

Renovation level $\bullet$ Org. $\odot$ Ref. $1 \bullet$ Ref. 2

Type $\bigcirc$ Detached $\triangle$ Semi-Detached $\otimes$ Terraced

Age class $\bullet 1 \bullet 2 \bullet 3$

Figure 3: Scatter plot of $C_{\mathrm{ADR}}$ as a function of $\eta_{\mathrm{ADR}}$ for the radiator (left) and floor heated building typologies for an ADR event of $4 \mathrm{~h}$. The shape and size of the markers show respectively the building type and age class, the color indicates the renovation level.

building. For the unrenovated detached dwellings, the storage efficiencies vary between $66 \%$ and $75 \%$ for an ADR-event of $4 \mathrm{~h}$ (81-93\% for floor heating). Thereby it should be noted that as an exception the detached buildings of Age Class 1 show a slightly higher $\eta_{\mathrm{ADR}}(2 \mathrm{pp})$ compared to the dwellings of Age Class 2, which is linked to the high thermal mass of the massive outer walls for Age class 1 compared to the uninsulated cavity wall for Age class 2 .

A mild renovation (Ref. 1) does not drastically improve $\eta_{\mathrm{ADR}}$ for the detached dwellings, since for these dwellings most heat is stored in the day-zone, while the mild renovation mainly affects the insulation of the night-zone by adding insulation in the roof. Hence, improving the insulation quality of the roof (Ref. 1 ) does not drastically affect $\eta_{\mathrm{ADR}}$. For the terraced and semi-detached dwelling the contribution of the night-zone in the total capacity for ADR is higher, resulting in a larger impact of roof insulation (Ref. 1).

When also the outer walls and floor are insulated (Ref. 2), storage efficiencies above $80 \%$ (90\% for floor heating) are found for all cases if the duration of the ADR-event is limited to 4 hours. Moreover, the relative differences between the age classes are reduced after insulation, with the exception of the oldest dwellings as the ratio of the thermal mass to the heat loss coefficient is significantly higher for these dwellings.

Finally, comparing the building types, the higher ratio of the thermal mass to the heat loss coefficient for the terraced buildings results in storage efficiencies that are 5-10 pp higher than for the other building types equipped with radiator heating. Moreover the effect of the mild renovations (Ref. 1) is more pronounced for the terraced buildings. The same level of increase in $\eta_{\mathrm{ADR}}$ is not shown for the terraced houses when the insulation quality is improved further to renovation level 2. Nevertheless, it should be noted here that for the thoroughly renovated dwellings the remaining differences in the results fall within the level of uncertainty of the reduced-order models and should be handled carefully.

In summary, Figure 3 shows the relation between $C_{\mathrm{ADR}}$ and $\eta_{\mathrm{ADR}}$ for the different buildings in the Belgian building stock for a storage period of $4 \mathrm{~h}$. Based 


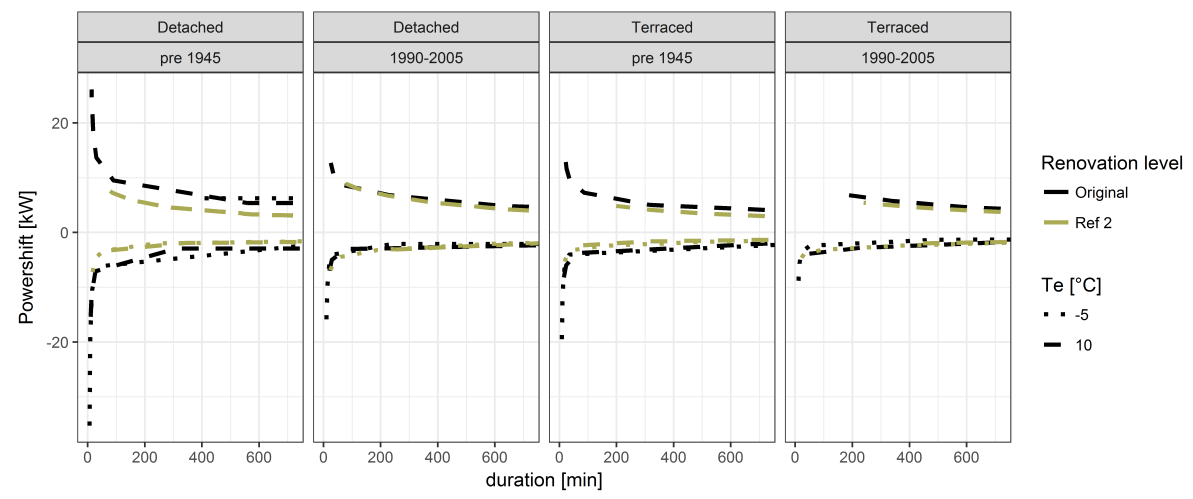

Figure 4: Power shifting capability (PSC) for the radiator heated buildings as function of the building type and the outdoor temperature for an initial indoor temperature of $21^{\circ} \mathrm{C}$.

on these theoretical characteristics, the highest operational savings due to ADR are expected for the floor heating buildings since they do not only show higher storage efficiencies, but also significantly higher available capacities. For the floor heated buildings, except for the oldest unrenovated and mildly renovated detached and semi-detached dwellings, all efficiencies are above $90 \%$, compared to variations between $65 \%$ and $91 \%$ for buildings equipped with radiators.

For the latter, the highest potential for ADR is expected for the mildly renovated terraced buildings built after 1990, since they show both high efficiencies $(87 \%$ - $91 \%$ ) and higher available capacities compared to the thoroughly renovated buildings. For the floor heating cases the operational savings due to ADR are expected to be less sensitive to $\eta_{\mathrm{ADR}}$ since high values are obtained for most buildings. Consequently, buildings with a higher capacity, i.e. the older and mildly renovated dwellings, are expected to have a higher impact on the operational savings and $\mathrm{CO}_{2}$-emission reductions. These results are in line with the findings of Patteeuw et al. 4, although the results obtained in that study show on average lower values of the storage efficiency which can be allocated to the impact of the occupancy profile and solar gains, as discussed below.

Figure 4 shows the results for the Power Shifting Capability (PSC) when the buildings are in a reference state with indoor air temperature of $21{ }^{\circ} \mathrm{C}$. The results are shown for the different building typologies and for an outdoor temperature of respectively $-5{ }^{\circ} \mathrm{C}$ and $10{ }^{\circ} \mathrm{C}$. As defined in Section 2 , the PSC shows the relation between a deviation of the thermal power on the vertical axis from the current operating point (power shift) and the duration this shift can be maintained on the horizontal axis. Hence the area between the curves for the upward and downward modulations covers all feasible operating points for demand response. As such, the PSC can provide valuable information to for instance grid operation during the planning and operation of flexible loads in balancing applications as it gives a direct relation between the aspects of power, duration and comfort constraints. It is clear that larger deviation in power can 
only be maintained for shorter periods. Figure 4 shows how the amplitude of the power shift for a given duration is function of the quality of the building. These results correspond to the results for $C_{\mathrm{ADR}}$ and indicate how also the amplitude of the downward power shift decreases as the insulation quality increases. The latter may be considered as counter-intuitive as a high insulation level would allow for the heating system to remain off for longer periods. However, these observations reflect that as the insulation quality improves the power used during normal operation and hence the potential for negative flexibility is lower. The same phenomena, i.e. the relation with the power in normal operation, explains the differences observed for the different outdoor temperatures. Thereby it is demonstrated that for an outdoor temperature of $-5{ }^{\circ} \mathrm{C}$ the curve for upward modulation is not for all buildings visible on the plot, since for these cold conditions the heating system is working close to its maximum power and a small increase of the power is unable to increase the temperature to the maximum comfort temperature. Hence, the curve moves to the right, outside the range of the plot.

\subsection{Impact of dynamic boundary conditions}

The results of the previous section - obtained for simplified, static boundary conditions - allowed to assess and contrast the theoretic potential of dwellings as a function of their thermal properties. As already observed in Figure 4 , the energy flexibility depends on the boundary conditions and is hence expected to be time-dependent. To evaluate this, this section illustrates the time-dependency of the ADR characteristics for the different building typologies of the Belgian residential stock. Therefore, $C_{\mathrm{ADR}}, \eta_{\mathrm{ADR}}$, and $P S C$ are quantified as a function of the start time of the ADR-event, whereby the consecutive ADR-events are assumed independent. Consequently the obtained results present predictions of the available flexibility if an ADR-event would start at that point in time and not the obtained flexibility. The simulations are conducted for the Belgian climate (Uccle) and the occupancy schedule shown in Table 3 a duration of the ADR-event of $2 \mathrm{~h}$ and a comfort range of $2{ }^{\circ} \mathrm{C}^{3}$. Thereby, it should be noted that the actual trends and numerical results observed below depend on the assumed dynamic boundary conditions. As in previous section, $C_{\mathrm{ADR}}$ and $\eta_{\mathrm{ADR}}$ are discussed first.

Figure 5 shows $C_{\mathrm{ADR}}$ as a function of the start time of the ADR-event and contrasts the radiator heated detached (left) and terraced buildings (right) built before 1945 (Age class 1) and between 1990-2005 (Age class 4). These building cases are shown here since they represent two significantly different cases in terms of insulation quality and heat loss to capacity ratio. Moreover, the figure shows the available capacity of the original buildings before renovation (top) and after thorough renovation (bottom). Similar trends were identified for the

\footnotetext{
${ }^{3}$ The duration and comfort range have been selected as they give good trade-off between available capacity and storage efficiency. Nonetheless, other values can be used depending on the application.
} 


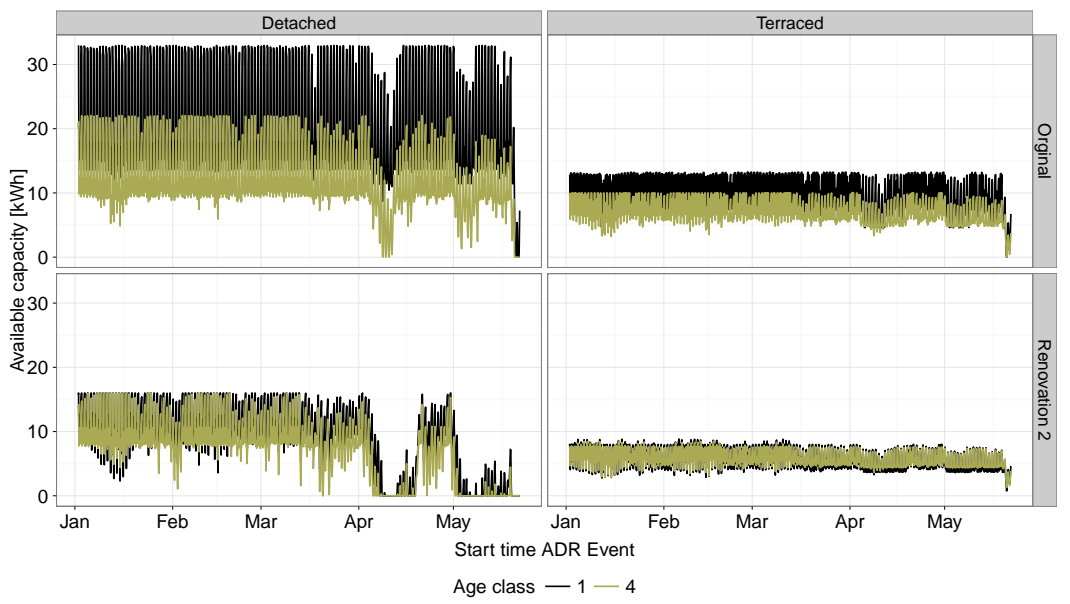

Figure 5: Available storage capacity as a function of the start time of the ADR-event for an ADR-event of $2 \mathrm{~h}$ with a comfort range of $2{ }^{\circ} \mathrm{C}$, contrasting the detached (left) and terraced (right) dwellings for both the original (top) and thoroughly renovated (bottom) cases. The different colors represent the radiator heated buildings built before 1945 (Age class 1) and between 1991-2005 (Age class 4).

other building typologies. By comparison, for the steady-state evaluation (Fig. 2. with an outdoor temperature of $5{ }^{\circ} \mathrm{C}$ the corresponding values for $C_{\mathrm{ADR}}$ were $18 \mathrm{kWh}$ and $14 \mathrm{kWh}$ for respectively the original detached and terraced dwellings built before 1945 and 12 and $8 \mathrm{kWh}$ for respectively the renovated detached and terraced dwellings built before 1945 .

Significant variations on two time scales are apparent from Figure 5. A longterm variation, showing decreasing values of the available capacity in mid-season when the outdoor temperature rises and solar gains become important. In addition an important daily variation is shown, as highlighted by the averaged daily profiles illustrated further in Figure6

The long-term variations result from reduction in heat demand due to the increasing outdoor temperatures and high solar gains. Moreover in mid-season and summer, the free-floating indoor temperatures will rise above the minimum comfort temperature, reducing the temperature difference that is available to activate the STES. Note that the impact of these effects is more pronounced for the detached dwelling due to the higher glazed area and therefore the higher solar gains and the lower ratio of the heat loss coefficient over the available thermal mass. In the renovated scenario, the high solar gains for the detached dwelling and the fact that shading is not included in the model, results in indoor temperatures above $22{ }^{\circ} \mathrm{C}$ for the period between April $2^{\text {nd }}$ and April $12^{\text {th }}$ and after May $4^{\text {th }}$. Consequently, the heating system can no longer be used to activate the thermal mass and the resulting available capacity for ADR is $0 \mathrm{kWh}$. Note that active cooling systems can be considered for ADR at this point, however this has not been investigated in this Belgian context. Moreover, one may argue that the use of shading devices may avoid the overheating and prolong 


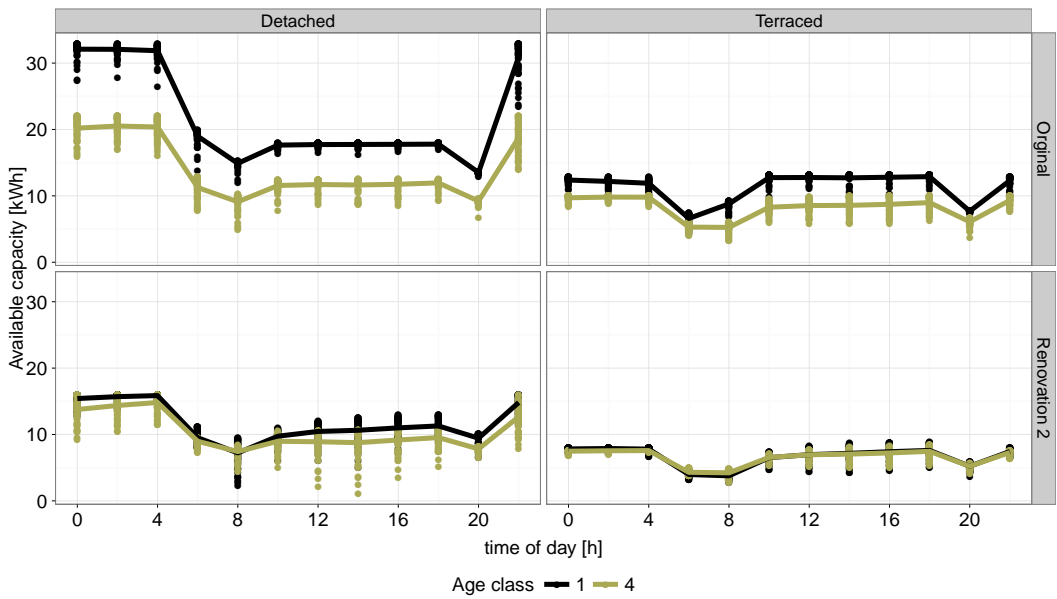

Figure 6: Averaged daily profile of the $C_{\mathrm{ADR}}$, contrasting the detached (left) and terraced (right) dwellings for both the original (top) and thoroughly renovated (bottom) cases. The different colors represent the buildings built before 1945 (Age class 1) and between 1991-2005 (Age class 4), for an ADR-event of $2 \mathrm{~h}$ with a comfort range of $2 \mathrm{C}$. The points show the obtained daily values, while the curve represents the averaged daily profile.

the active use of the structural thermal energy storage capacity. In both cases, it is the authors opinion that passive strategies should be given priority to deliver thermal comfort. This statement is supported by the results of the storage efficiency which are discussed further in Figure 7.

In addition to the long-term variations, daily fluctuations induced by the occupancy schedule are illustrated in Figure6. Since, the maximum temperature in the ADR-event $\left(T_{\max , A D R}\right)$ is calculated based on the temperature set-point for the occupied period, a larger range of temperature variations is available during the set-back periods as the ADR event will start from lower indoor temperatures.

To illustrate this effect in more detail Figure 6 shows an average daily profile of $C_{\mathrm{ADR}}$ for the cases shown in Figure 5. Thereby a clear difference is found between the profile of the terraced and the detached dwelling. Whereas for the detached dwelling the available capacity is almost 2 times higher between 10 $\mathrm{PM}$ and $4 \mathrm{AM}$, the available capacity for the terraced building is almost equal during day-time as at night. This can be explained by the significant difference between the share of the day- and night-zone in the total heating power. For the detached dwelling the heating power for the day-zone is on average twice as high as for the night-zone. Consequently, the additional capacity that is available in the day-zone during the temperature set-back at night, is higher than the additional capacity that is available in the night-zone between $9 \mathrm{AM}$ and $9 \mathrm{PM}$. For the terraced buildings, both zones have an equal share in the heating power, resulting in less significant daily variations.

The reduction in the capacity between $6 \mathrm{AM}$ and $8 \mathrm{AM}$ and at $8 \mathrm{PM}$, coincide with the start-up of respectively the day- and night-zone. During this period 


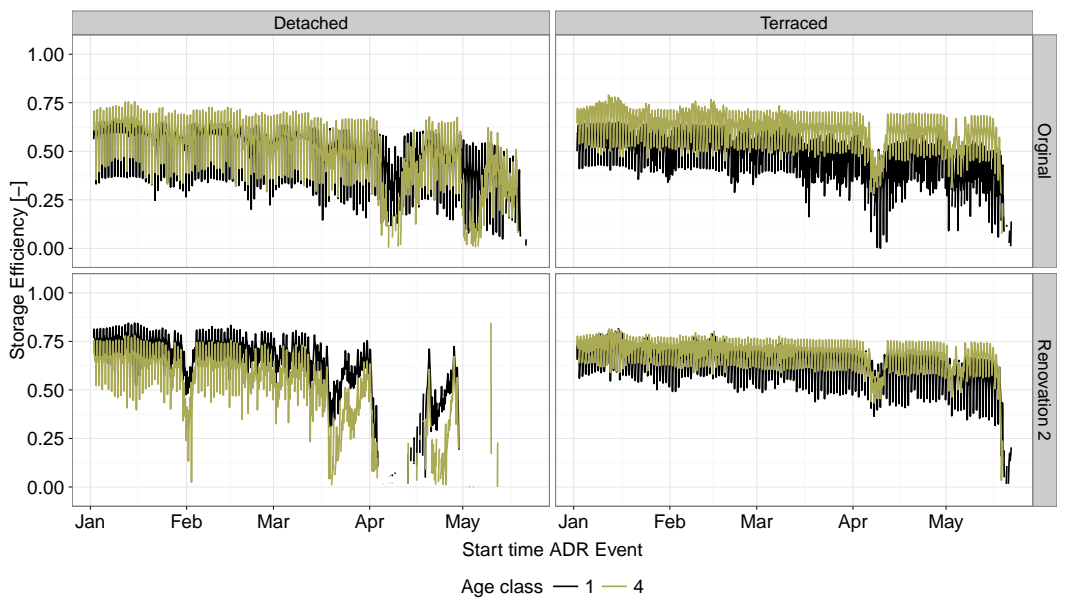

Figure 7: Storage efficiency as a function of the start time of the ADR-event for an ADRevent of $2 \mathrm{~h}$ with a comfort range of $2{ }^{\circ} \mathrm{C}$, contrasting the detached (left) and terraced (right) dwellings for both the original (top) and thoroughly renovated (bottom) cases. The different colors represent the buildings built before 1945 (Age class 1) and between 1991-2005 (Age class 4).

the heating in the reference case already operates at its maximum capacity to recover from the temperature setback and is therefore not available for ADR.

Complementary to $C_{\mathrm{ADR}}$, Figure 7 shows the evolution of the storage efficiency. Thereby, a slow, systematic decrease of $\eta_{\mathrm{ADR}}$ is found in addition to the daily variations and the significant reduction of the storage efficiency for periods with high solar gains. While the latter are directly linked to the variations found in Figure 5, the systematic reduction is explained by the decreasing heat demand of the dwellings as the outdoor temperature rises. To analyze this effect the relative available storage capacity $\left(C_{A D R, r e l}\right)$ is calculated as:

$$
C_{A D R, r e l}=\frac{C_{\mathrm{ADR}}}{\int_{0}^{24 h} Q_{R e f} d t}
$$

with $Q_{R e f}$ the heat demand without ADR. Thereby, a systematic increase of the relative storage capacity is found as a function of time - due to the increasing outdoor temperature - which corresponds to the systematic reduction of the efficiency found in Figure 7. During the winter period, the heat stored during the ADR-event with a duration of $2 \mathrm{~h}$ corresponds on average to $3 \%-10 \%$ of the daily heat demand for the original dwellings and between $5 \%$ and $20 \%$ for the thoroughly renovated buildings. $C_{A D R, \text { rel }}$ increases rapidly in periods with high solar gains, especially for the detached dwelling given the higher window to floor area ratio. Consequently, the storage efficiency during these periods drops to $0 \%$ as $C_{A D R, \text { rel }}$ is close to $100 \%$. In other words, as $C_{A D R, \text { rel }}$ increases it takes longer before the stored heat can be used, resulting in higher losses. The potential for ADR using the structural storage capacity using only heating 


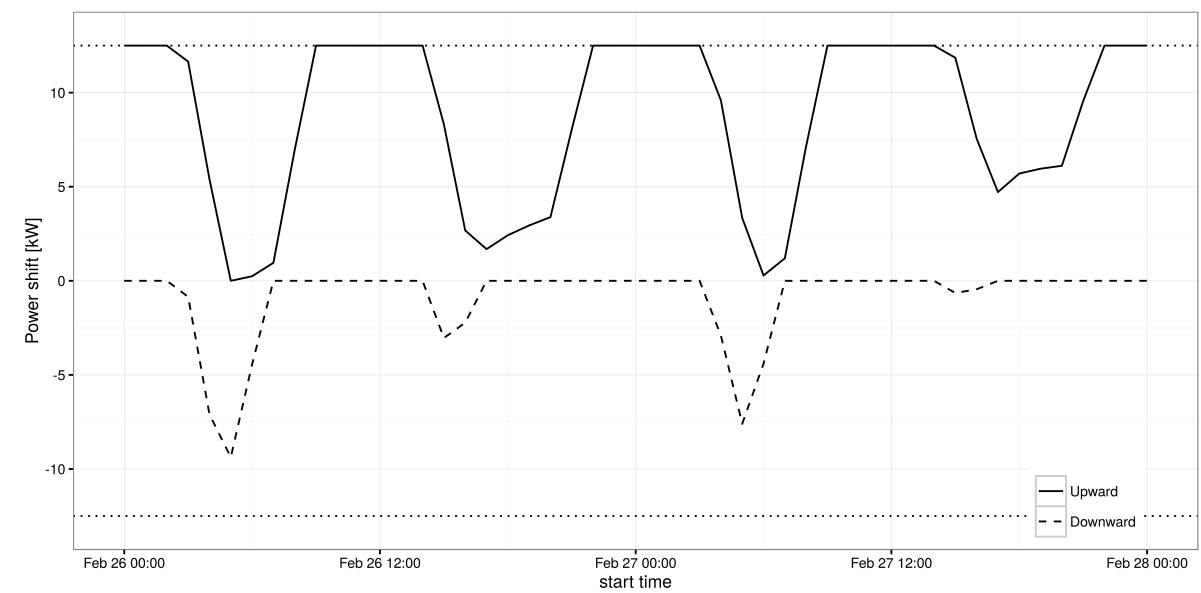

Figure 8: Power shifting capability results for $2 \mathrm{~h}$ duration as function of the starting time. The results are shown for the unrenovated detached dwelling built between 1990-2005. The dotted lines represent the nominal thermal power of the heating system.

systems is thus clearly limited to the heating season. Finally, Figure 8 shows an example of a representation of the results for the dynamic evaluation of the power shifting capability. While the calculation method enables to calculate the complete PSC profiles, as represented in Figure 4, Figure 8 shows the evolution upward and downward power shift for a duration of $2 \mathrm{~h}$ in function of the starting time of the ADR event. Hence, the curve shows the maximum power increase or decrease during a period of $2 \mathrm{~h}$ if the ADR event would start from the reference scenario at that point in time. As a reference scenario the results of an optimal control problem that minimizes the annual heat demand was used. In line with the results for $C_{\mathrm{ADR}}$, a clear reduction of the upward power shift is found in the morning and the evening when a high fraction of the installed heating power is already used to provide minimum comfort. Hence only limited power is available for flexibility. Also for most of the day the negative flexibility is $0 \mathrm{~kW}$, since no heating is needed during the unoccupied hours. Although, less visible from Figure 8 a similar dependence of the PSC to the exterior boundary conditions was obtained. As the outdoor temperature rises and solar gains become more important the upward and downward power shift respectively increase and decrease. The latter results mainly from a reduction of the reference demand.

\section{Conclusions}

A generic, dynamic quantification method for energy flexibility, or the potential for active demand response, has been presented. The methodology is based on the quantification of 3 performance indicators for energy flexibility that capture flexibility in the dimensions of size, time and induced losses or cost. Comprehensive definitions and corresponding quantification methods for 
these indicators have been established for the application of structural thermal energy storage in buildings. Nonetheless, as the quantification methods consider only the ingoing and outgoing energy flows of the system, it was argued that the method can be readily extended to other demand response and storage applications. Additionally, the quantification methods were formulated independent of the internal control of the building. A rule-based approach was exploited in this paper to facilitate a comprehensive analysis of the indicators for different building typologies. For more complex systems optimal control formulations may be used to simulate the ADR event.

The indicators have been used to asses the active demand response potential of structural thermal energy storage in the different residential building typologies of the Belgian building stock. This analysis was split into two parts. First, a theoretic quantification was carried out assuming simplified and static boundary conditions. From a methodological point it was shown how the quantification of the proposed indicators under these simplified boundary conditions allowed for a comprehensive evaluation of the ADR potential. This approach allowed to easily compare the ADR potential, or energy flexibility, as function of the building typologies and control parameters. The results show that in order to avoid a strong decrease in storage efficiencies, the application of STES should be limited to short ADR events, especially in the case of radiator heating. An available storage capacity for ADR between $12-30 \mathrm{kWh}$ was obtained for the radiator heated buildings and $16-66 \mathrm{kWh}$ for the floor heating cases, assuming an ADR-event of $4 \mathrm{~h}$ and a comfort range of $2{ }^{\circ} \mathrm{C}$. The corresponding efficiencies obtained for the simplified boundary conditions, assuming a constant outdoor temperature of $5{ }^{\circ} \mathrm{C}$, were found to vary between $66 \%$ and $85 \%$ for the original dwellings equipped with radiator heating, while after renovation all efficiencies were above $80 \%$. For the floor heating cases, the impact of renovation was less pronounced since for most cases efficiencies above $90 \%$ were already obtained for the simplified boundary conditions.

In the second part of the analysis, the dynamic formulation of the quantification methods was exploited to evaluate the impact of dynamic boundary conditions on the obtained energy flexibility. In a qualitative analysis a significant decrease of $C_{\mathrm{ADR}}$ and $\eta_{\mathrm{ADR}}$ was demonstrated as the reference heat demand decreases as a result of increasing outdoor temperatures and solar gains. Moreover, the impact of occupant behavior, in terms of occupancy period, was found to have a significant impact on the instantaneous available flexibility. While this analysis was conducted in a qualitative way, the results clearly demonstrate the potential of the indicators to quantify these dynamic effects and emphasize the need for an dynamic evaluation of energy flexibility in an operational phase.

\section{Acknowledgments}

This project receives the support of the European Union, the European Regional Development Fund ERDF, Flanders Innovation \& Entrepreneurship and the Province of Limburg. 


\section{References}

[1] R. Baetens, R. De Coninck, J. Van Roy, B. Verbruggen, J. Driesen, L. Helsen, D. Saelens, Assessing electrical bottlenecks at feeder level for residential net zero-energy buildings by integrated system simulation, Applied Energy 96 (2012) 74-83. doi:10.1016/j.apenergy.2011.12.098 URL http://linkinghub.elsevier.com/retrieve/pii/ S0306261912000037

[2] P. D. Lund, J. Lindgren, J. Mikkola, J. Salpakari, Review of energy system flexibility measures to enable high levels of variable renewable electricity, Renewable and Sustainable Energy Reviews 45 (2015) 785-807. doi:10.1016/j.rser.2015.01.057 URL http://linkinghub.elsevier.com/retrieve/pii/ S1364032115000672

[3] P. Siano, D. Sarno, Assessing the benefits of residential demand response in a real time distribution energy market, Applied Energy 161 (2016) 533-551. doi:10.1016/j. apenergy .2015.10.017. URL http://linkinghub.elsevier.com/retrieve/pii/ S0306261915012441

[4] D. Patteeuw, G. Reynders, K. Bruninx, C. Protopapadaki, E. Delarue, W. D'haeseleer, D. Saelens, L. Helsen, CO2-abatement cost of residential heat pumps with active demand response: demandand supply-side effects, Applied Energy 156 (2015) 490-501. doi:10.1016/j.apenergy.2015.07.038.

URL http://linkinghub.elsevier.com/retrieve/pii/ S0306261915008673

[5] Y. Sun, S. Wang, F. Xiao, D. Gao, Peak load shifting control using different cold thermal energy storage facilities in commercial buildings: A review, Energy Conversion and Management 71 (2013) 101-114. doi:10.1016/j.enconman.2013.03.026.

URL http://linkinghub.elsevier.com/retrieve/pii/ S0196890413001696

[6] E. Nyholm, S. Puranik, É. Mata, M. Odenberger, F. Johnsson, Demand response potential of electrical space heating in Swedish single-family dwellings, Building and Environment 96 (2016) 270-282. doi:10.1016/j.buildenv.2015.11.019.

URL http://linkinghub.elsevier.com/retrieve/pii/ S0360132315301815

[7] I. Dincer, Thermal energy storage systems as a key technology in energy conservation, International Journal of Energy Research 26 (7) (2002) 567588. doi:10.1002/er.805.

URL http://doi.wiley.com/10.1002/er.805 
[8] J. Kensby, A. Trüschel, J.-O. Dalenbäck, Potential of residential buildings as thermal energy storage in district heating systems Results from a pilot test, Applied Energy 137 (2015) 773-781. doi:10.1016/j.apenergy.2014.07.026.

URL http://linkinghub.elsevier.com/retrieve/pii/ S0306261914007077

[9] G. Reynders, T. Nuytten, D. Saelens, Potential of structural thermal mass for demand-side management in dwellings, Building and Environment 64 (2013) 187-199. doi:10.1016/j.buildenv.2013.03.010.

URL http://linkinghub.elsevier.com/retrieve/pii/ S0360132313000905

[10] M. Stötzer, I. Hauer, M. Richter, Z. a. Styczynski, Potential of demand side integration to maximize use of renewable energy sources in Germany, Applied Energy 146 (2015) 344-352. doi:10.1016/j.apenergy.2015.02.015.

URL http://linkinghub.elsevier.com/retrieve/pii/ S0306261915001889

[11] K. Heussen, S. Koch, A. Ulbig, G. Andersson, Unified System-Level Modeling of Intermittent Renewable Energy Sources and Energy Storage for Power System Operation, IEEE Systems Journal 6 (1) (2012) 140-151. doi:10.1109/JSYST . 2011.2163020.

URL http://ieeexplore.ieee.org/lpdocs/epic03/wrapper.htm? arnumber=6018245http://ieeexplore. ieee.org/document/6018245/

[12] M. Geidl, G. Koeppel, P. Favre-Perrod, B. Klockl, G. Andersson, K. Frohlich, Energy hubs for the future, IEEE Power and Energy Magazine 5 (1) (2007) 24-30. doi:10.1109/MPAE.2007.264850.

URL http://ieeexplore .ieee.org/document/4042137/

[13] F. Oldewurtel, T. Borsche, M. Bucher, P. Fortenbacher, M. Gonz, T. Haring, J. L. Mathieu, M. Olivier, E. Vrettos, A Framework for and Assessment of Demand Response and Energy Storage in Power Systems a, in: 2013 IREP Symposium-Bul Power System Dynamics and Control, 2013, pp. 1-24.

[14] R. De Coninck, L. Helsen, Quantification of flexibility in buildings by cost curves Methodology and application, Applied Energy 162 (2016) 653-665. doi:10.1016/j.apenergy.2015.10.114. URL http://dx.doi.org/10.1016/j.apenergy.2015.10.114http: //linkinghub.elsevier.com/retrieve/pii/S0306261915013501

[15] H. Wolisz, H. Harb, P. Matthes, Dynamic simulation of thermal capacity and charging/discharging performance for sensible heat storage in building wall mass, ... Building Simulation ... (2013) 2716-2723.

URL http://www.ibpsa.org/proceedings/BS2013/p\{_\}1371.pdf 
[16] S. Stinner, K. Huchtemann, D. Müller, Quantifying the operational flexibility of building energy systems with thermal energy storages, Applied Energy 181 (2016) 140-154. doi:10.1016/j.apenergy.2016.08.055. URL http://linkinghub.elsevier.com/retrieve/pii/ S0306261916311424

[17] R. De Coninck, R. Baetens, D. Saelens, A. Woyte, L. Helsen, Rule-based demand-side management of domestic hot water production with heat pumps in zero energy neighbourhoods, Journal of Building Performance Simulation 7 (4) (2014) 271-288. doi:10.1080/19401493.2013.801518. URL http://www.tandfonline.com/doi/abs/10.1080/19401493.2013. 801518

[18] G. Reynders, J. Diriken, D. Saelens, Bottom-up modeling of the Belgian residential building stock : influence of model complexity, in: SSB 2014, 2014, pp. 1-19.

[19] W. Cyx, N. Renders, M. Van Holm, S. Verbeke, IEE TABULA - Typology Approach for Building Stock Energy Assessment, Tech. Rep. August (2011).

[20] R. Baetens, R. De Coninck, F. Jorissen, D. Picard, L. Helsen, D. Saelens, OpenIDEAS - An Open Framework for Integrated District Energy Assessments, in: Proceedings of the 14th IBPSA Conference - Building Simulation 2015, Hyderabad, India, 2015.

[21] G. Reynders, Quantifying the impact of building design on the potential of structural storage for active demand response in residential buildings, Phd-thesis, KU Leuven (2015).

[22] A.-J. N. Khalifa, Natural convective heat transfer coefficient a review, Energy Conversion and Management 42 (4) (2001) 505-517. doi:10.1016/S0196-8904(00)00043-1.

URL http://www.sciencedirect.com/science/article/pii/ S0196890400000431http://linkinghub.elsevier.com/retrieve/ pii/S0196890400000431

[23] H. Awbi, A. Hatton, Mixed convection from heated room surfaces, Energy and Buildings 32 (2) (2000) 153-166. 10.1016/S0098-8472(99)00063-5.

URL http://linkinghub.elsevier.com/retrieve/pii/ S0098847299000635

[24] T. Defraeye, B. Blocken, J. Carmeliet, Convective heat transfer coefficients for exterior building surfaces: Existing correlations and CFD modelling, Energy Conversion and Management 52 (1) (2011) 512-522. doi:10.1016/ j.enconman.2010.07.026. 
[25] D. C. Hamilton, W. R. Morgan, Radiant-interchange configuration factors, Tech. rep., Tech. rep., National Advisory Comittee for Aeronautics, Washington (1952).

[26] CEN, EN 12831 Heating systems in buildings - Method for calculation of the design heat load (2003).

[27] Meteotest, METEONORM Version 6.1 - Edition 2009 (2008).

[28] R. Baetens, On externalities of heat pump-based low-energy dwellings at the low-voltage distribution grid, Phd theisi, KU Leuven (2015).

[29] Z. Liao, M. Swainson, A. Dexter, On the control of heating systems in the UK, Building and Environment 40 (3) (2005) 343-351. doi:10.1016/j.buildenv.2004.05.014.

URL http://linkinghub.elsevier.com/retrieve/pii/ S0360132304001842

[30] J. Le Dréau, P. Heiselberg, Energy flexibility of residential buildings using short term heat storage in the thermal mass, Energy 111 (8) (2016) 991-1002. doi:10.1016/j.energy.2016.05.076.

URL http://linkinghub.elsevier.com/retrieve/pii/ S0360544216306934 